تأثير ميزان فاصله از رودخانه بر خصوصيات فيزيكى و شيميايى، كلنيزاسيون و اسيورزايى

قارجهاى ميكوريز اربوسكولار همزيست با درختجِه گز (Tamarix arceuthoides)

ساره مرادى بهبهانى '، مصطفى مرادى '، رضا بصيرى' و جواد ميرزايى '

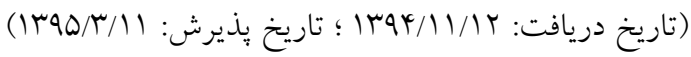

DOI: 10.18869/acadpub.jstnar.20.78.67

جִكيده

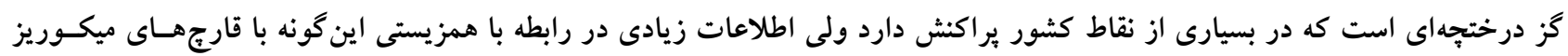

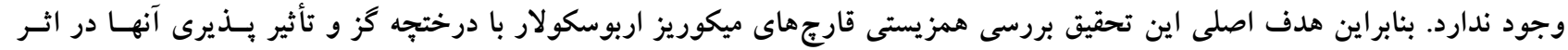

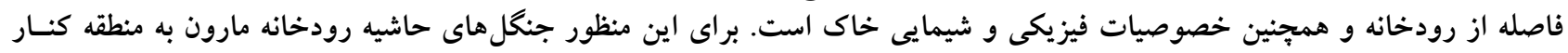

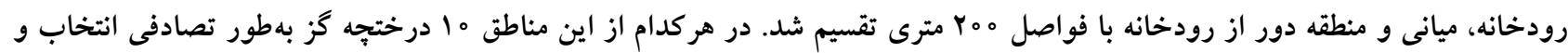

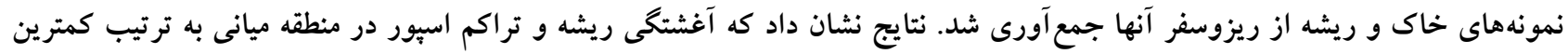

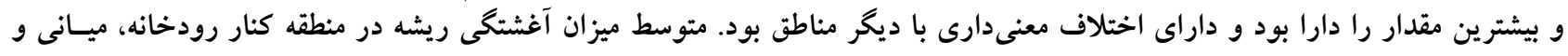

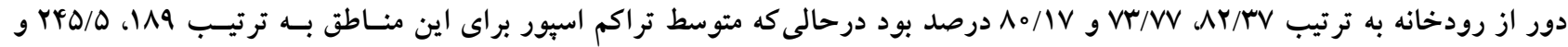

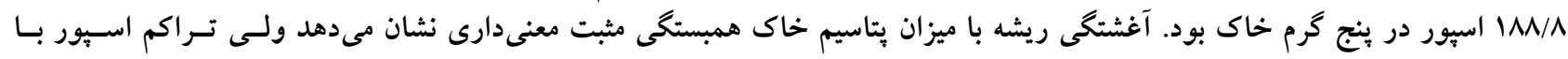

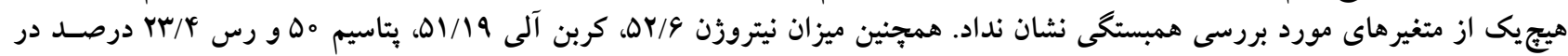

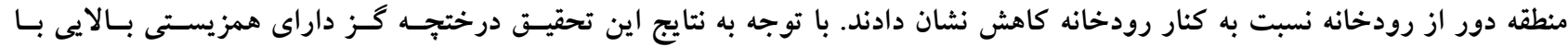

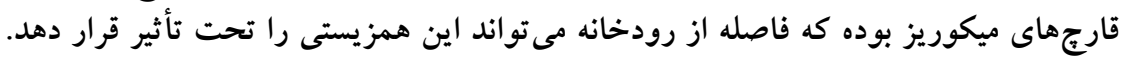

كلمات كليدى: يتاسيم، تراكم اسِور، فسفر، قارج ميكوريز، گز، آغشتخى

1. كُوه جنگلدارى، دانشكده منابع طبيعى، دانشخاه صنعتى خاتمالانبياء به.8هان

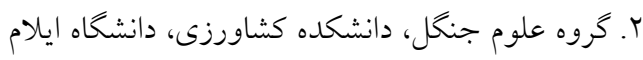

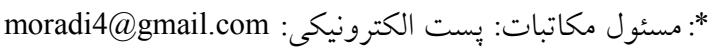


باعث افزايش خطر آتشسوزى در جنغل ها شود (rآ).

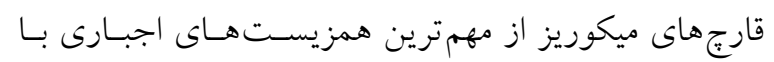

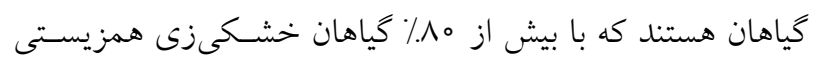

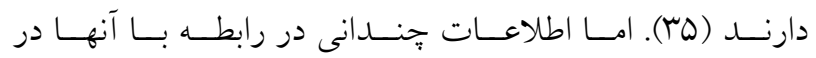

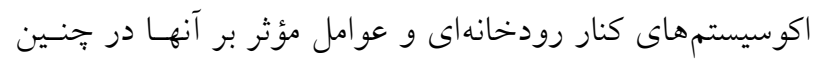

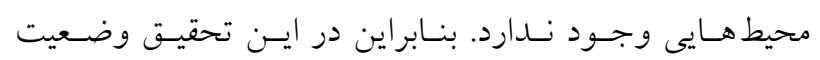

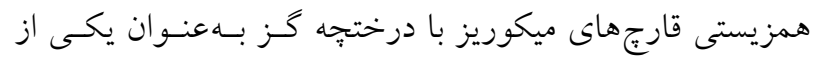

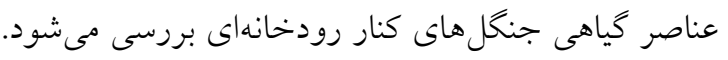

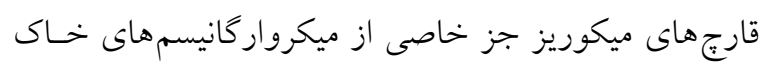

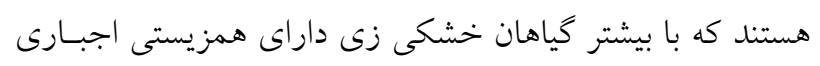

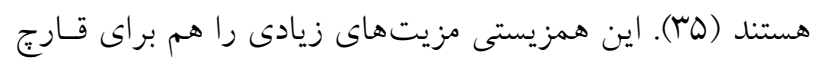

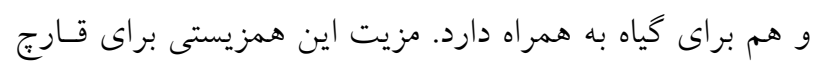

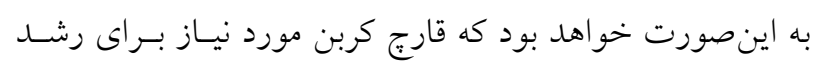

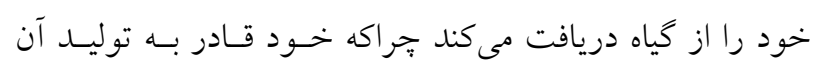

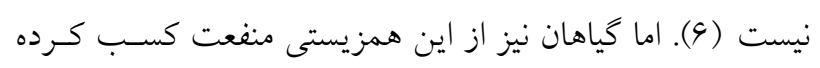

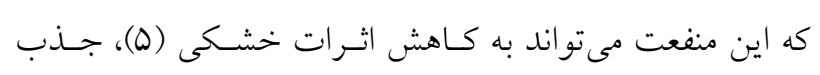

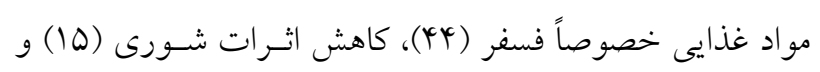
جذب آب (†) اشاره كرد.

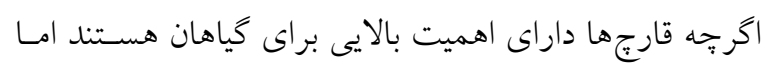

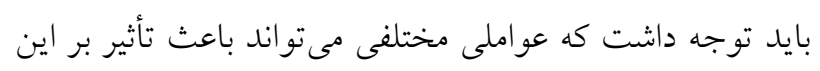

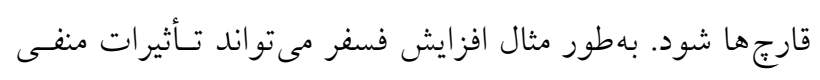

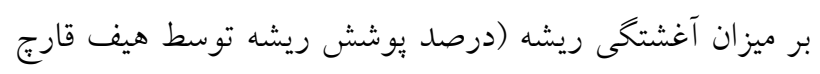

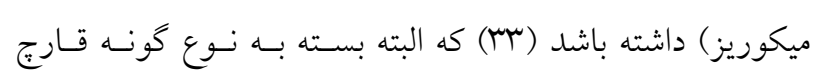

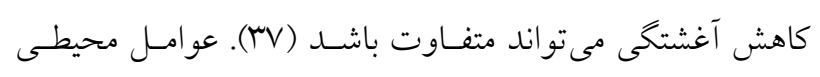

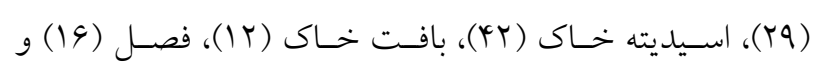

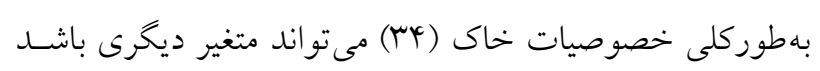
كه مى تواند وضعيت اين قارجهاى را تحت تأثير قرار دهد.

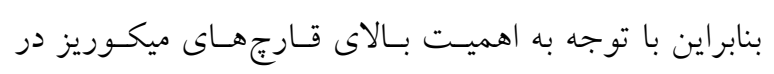

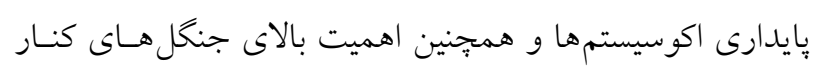

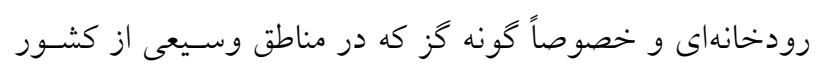

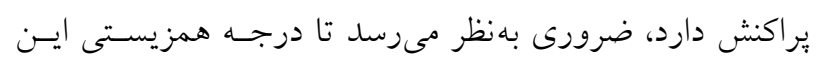

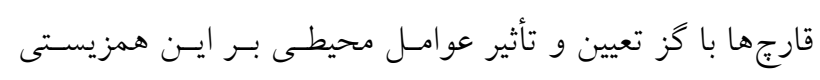

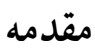

جنغل هاى حاشيهاى رودخانه محيطهاى منحصر بهفردى هستند

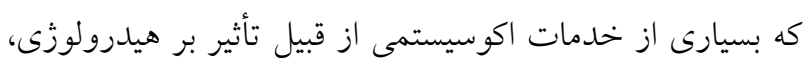

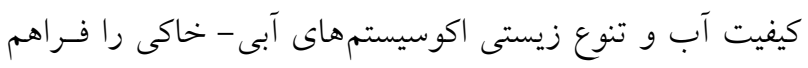

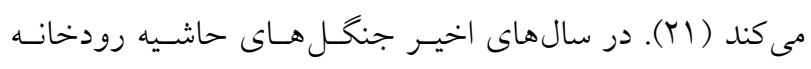

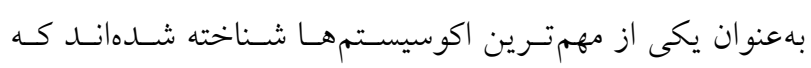

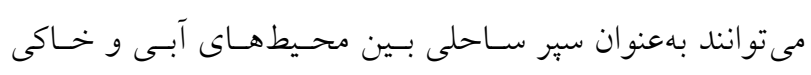

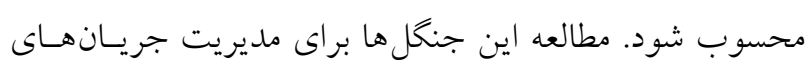

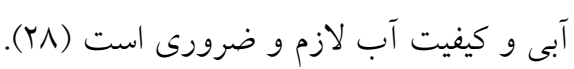

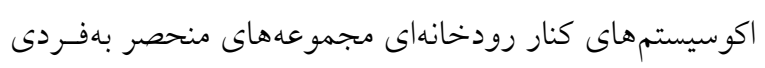

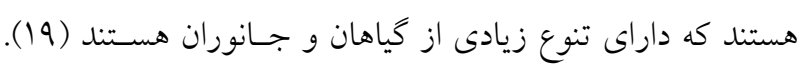

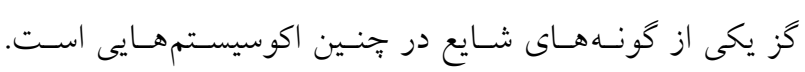

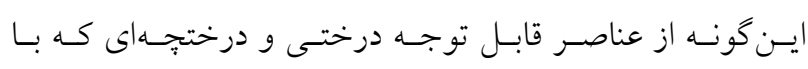

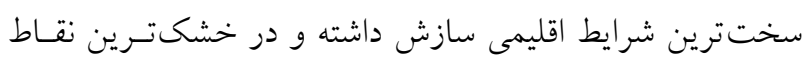

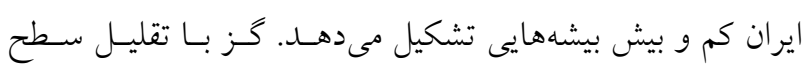

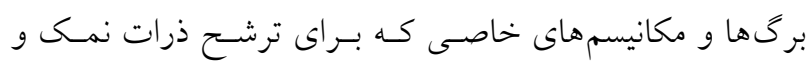

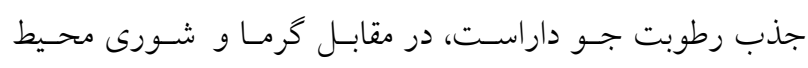

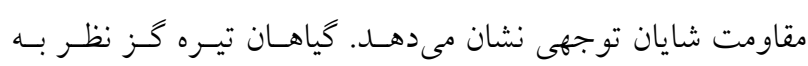

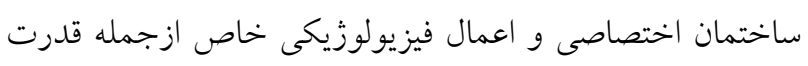

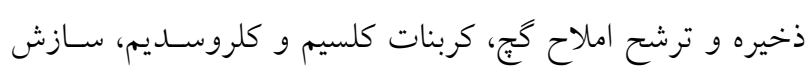

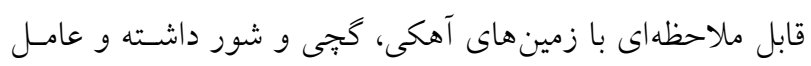

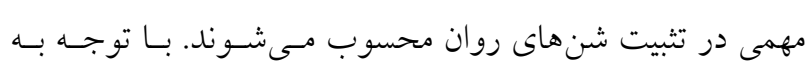

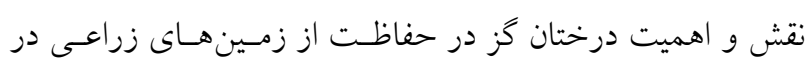

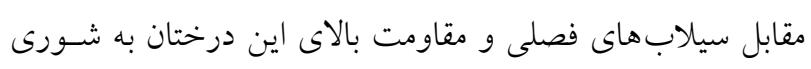

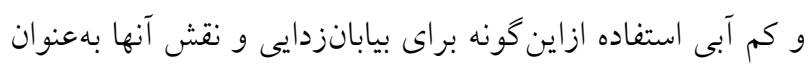

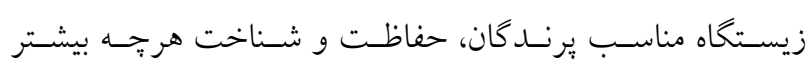

$$
\text { اين گونه امرى مهم محسوب مىشود (Y). }
$$

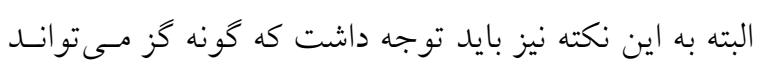

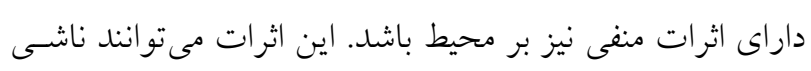

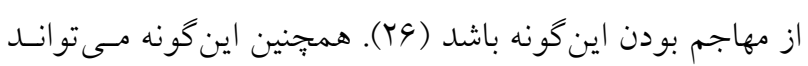

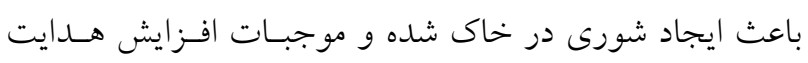

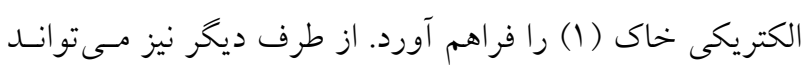




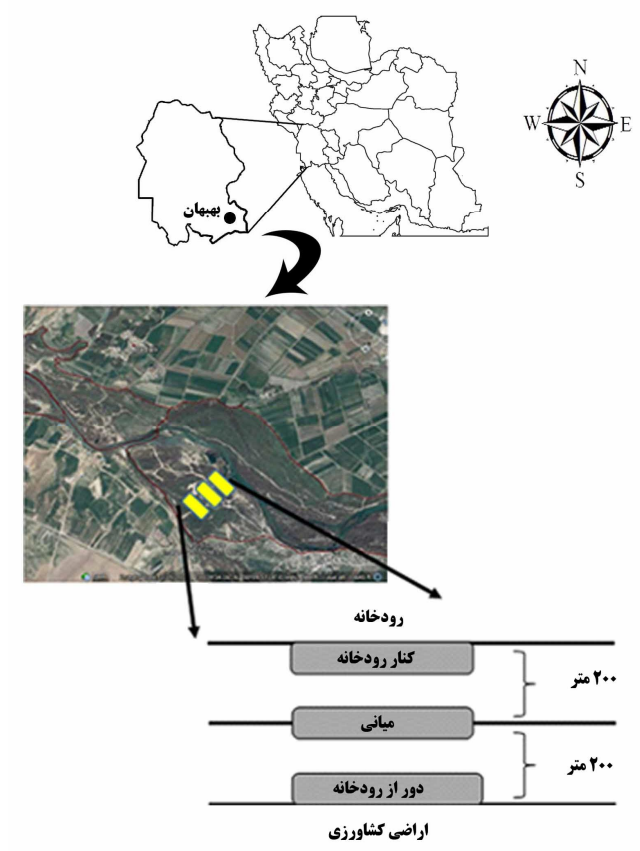

شكل 1. موقعيت منطقه مورد مطالعه

وضعيت همزيستى گز با قـارجهـاى ميكـوريز در كشـور هنـوز

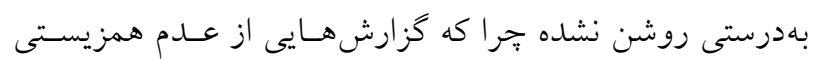
Tamarix hispida اينرو اهداف اين تحقيـق شـامل بررسى همزيسـتى قـارجهـاى

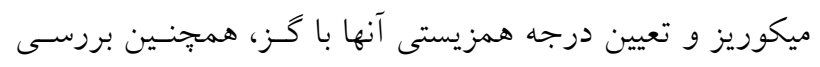

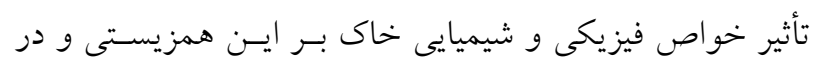

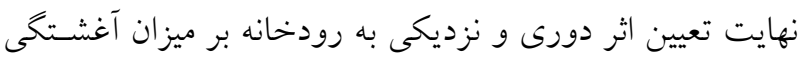

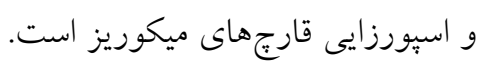

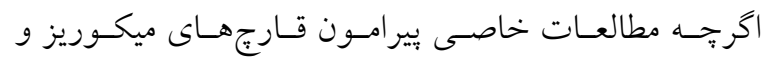

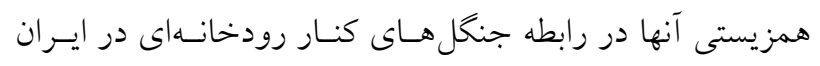

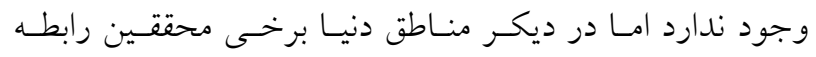

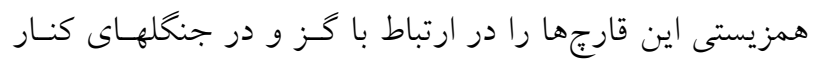
رودخانهاى بررسى نمودهاند (V، سأ و ه广).

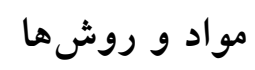

منطقه مورد مطالعه

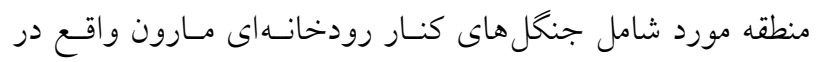
شهرستان به.بهان، استان خوزستان است. اين جنگل ها در محدوده
مشخص شود. جنكل هاى كنار رودخانهاى اكوسيستمهـاى غنسى هستند كه وظايف مهمى مثل كنتـرل سـيلاب، ايجـاد زيستـاهـاه

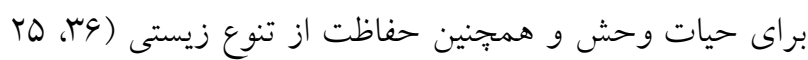

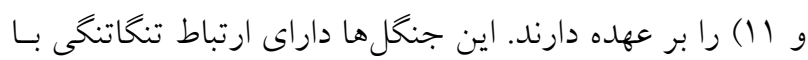

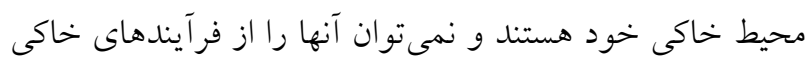

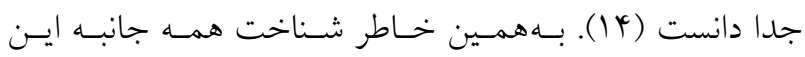

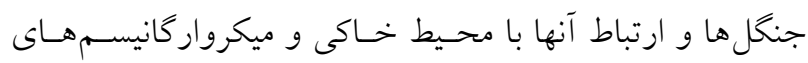
خاك ضرورى بهنظر مىرسد. متأسفانه تاكنون تحقيقى در رابطه ونه با قارجهاى ميكوريز در جنگكل هاى كنار رودخانـهاى در كشـور

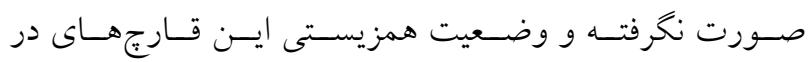

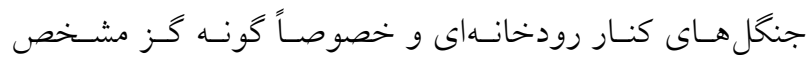

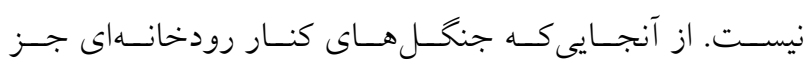

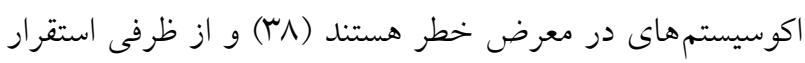

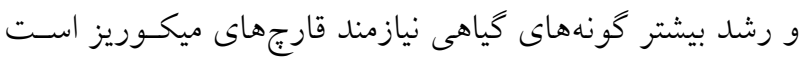

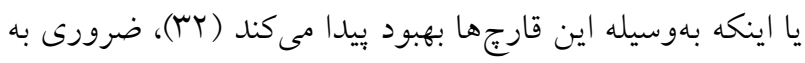
نظر مىرسد تا از وضعيت همزيستى ميان كياهان موجود در اين

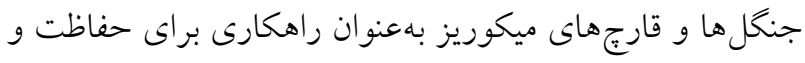

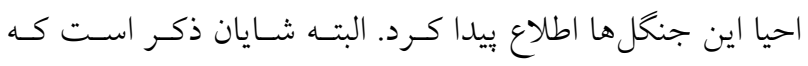




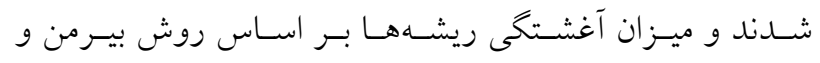

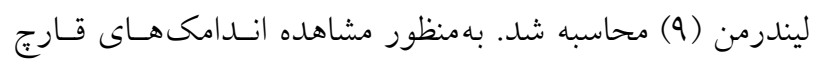

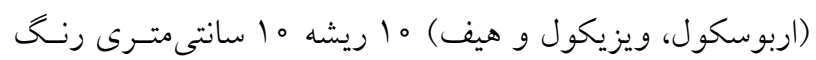

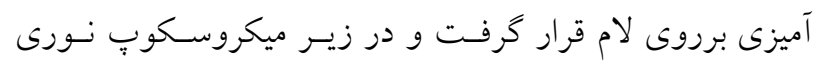
برسى گرديد.

\section{خصوصيات فيزيكى و شيميايى خاك}

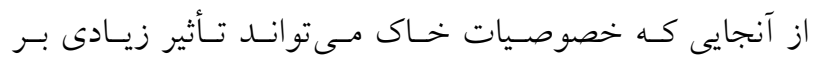
همزيستى قارجهاى ميكوريز داشته باشد، در اين مطالعه برخسى

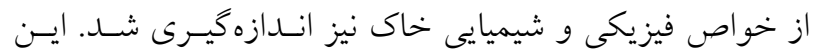

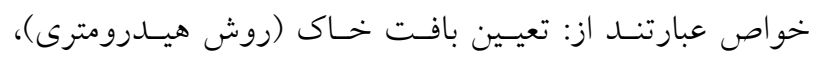
pH اسيديته خاك به (روش يتانسيومترى و با استفاده از دستخاه

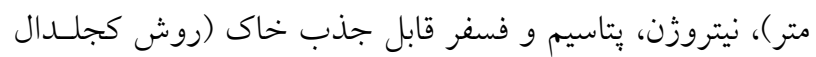

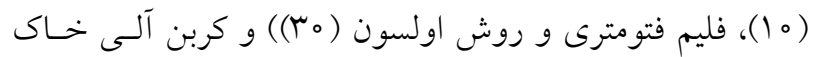

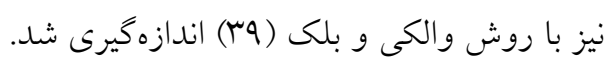

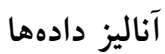

براى بررسى وضعيت خصوصسيات فيزيكى و شـيميايى خـاك

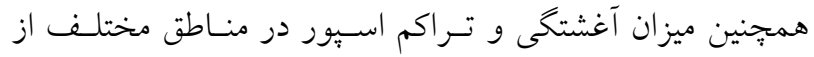

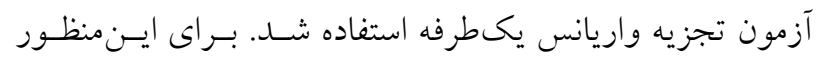

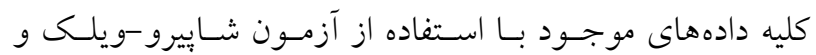
همخنى واريانس ها با استفاده از آزمون ليون مورد ارزيسابى قـرار

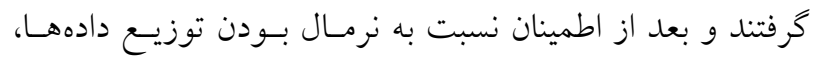

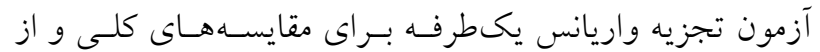

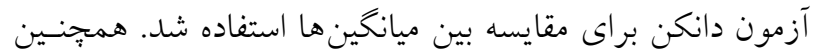
بهمنظور بررسى همبستخى بين متغيرهاى مورد بررسى از آزمون

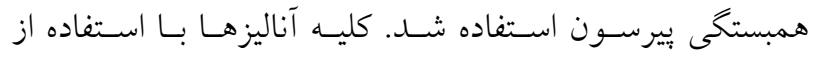

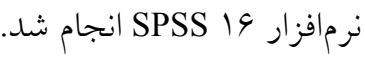

نتايج خصوصيات فيزيكى و شيمايى خاك

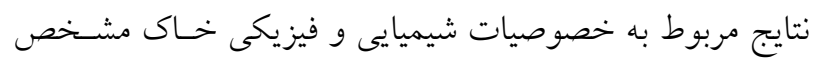

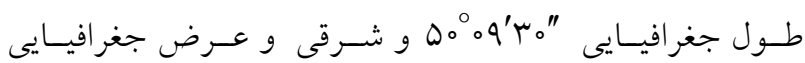
ز

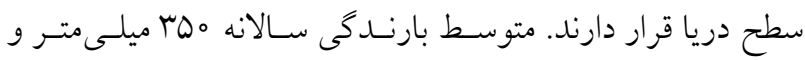

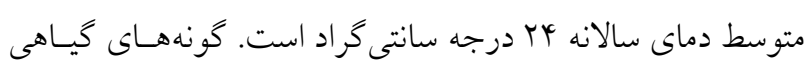

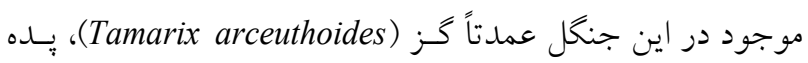
(Populus euphratica) كونههاى علفى و درختى مىباشد.

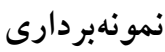

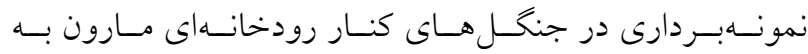
اينصورت انجام گرفت كه بهناى جنغل به سـه منطقـه تقسيم

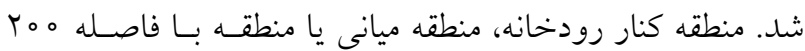

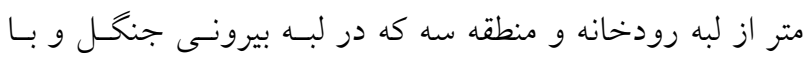

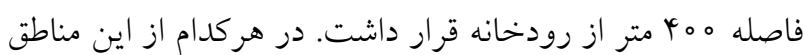

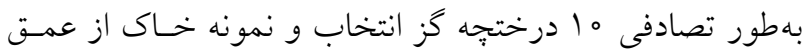
صفر تا ه ا سانتى مترى ريزوسفر برداشت شد. ريشههاى مـويين

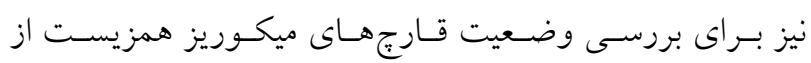

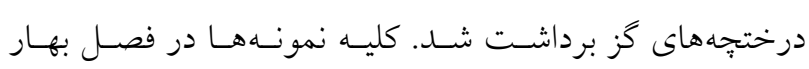
برداشت در كوتاهترين زمان به آزمايشگاه منتقل شد (Y9) بـودئ.

\section{استخراج اسبور از خاك و محاسبه درصد آغشتخى}

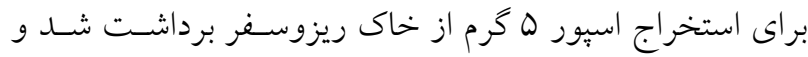

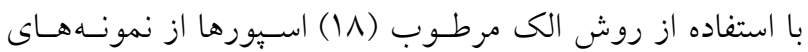

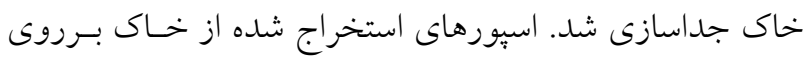
كاغذ صافى قرار گرفت و شمارش اسـيورهاى سـالم بـهمنظـور

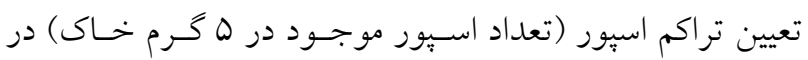

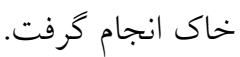

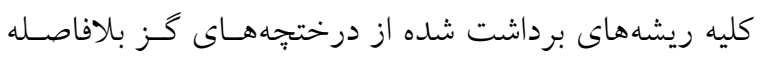

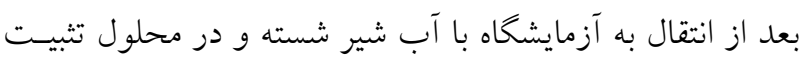

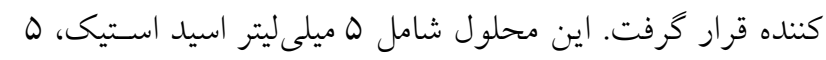

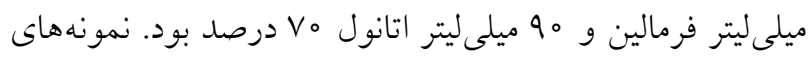

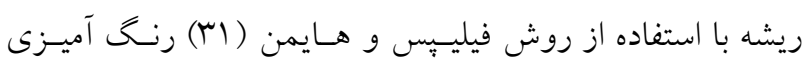


جدول ا. خصوصيات فيزيك و شيميايى خاك در منطقه مورد مطالعه (ميانخين 土 اشتباه معيار)

\begin{tabular}{|c|c|c|c|}
\hline منطقه دور از رودخانه & منطقه ميانى & كنار رودخانه & \\
\hline$\circ / \circ q_{ \pm} \circ / \circ \varphi^{b}$ & $0 / 19_{ \pm} 0 / 01 \wedge^{\mathrm{ab}}$ & $0 / 19 \pm 0 / 0 r q^{a}$ & نيتروزن (درصد) \\
\hline$\circ / \vee \wedge \pm \circ / \backslash \wedge^{b}$ & $1 /\left.\mu_{ \pm} c_{0 / 1}\right|^{\mathrm{cab}}$ & $1 / 9 \varphi_{ \pm 0 / T q^{a}}$ & كربن الى (درصد) \\
\hline $1 / 0 \pm 0 / 19 a$ & $q / \circ \pm \varphi / q^{a}$ & $Y / \Lambda \pm Y / \Delta^{a}$ & فسفر (ميلى گرم در كيلو گرم) \\
\hline $\mid \psi \wedge / \circ \pm V / \circ \Delta^{b}$ & $19 \Lambda / 9 \pm 11 / 9 \mathrm{ab}$ & $r \Delta \circ / \Lambda \pm Y Q / \Delta^{a}$ & يتاسيم (ميلى گرم در كيلو گرم) \\
\hline$V / T_{ \pm} \circ / Y^{b}$ & $q / 4 \pm 0 / v^{a}$ & $9 / 4 \pm 0 / 0^{a}$ & رس (درصد) \\
\hline $14 / 9 \pm 1 / Y^{b}$ & $r Y / \Lambda \pm \circ / \Lambda^{a}$ & $1 \Lambda / \wedge \pm Y / q^{a b}$ & سيلت (درصد) \\
\hline$V N / T \pm I / \Gamma^{\mathrm{a}}$ & $9 N / Y_{ \pm 0}+/^{b}$ & $V Y / \circ \pm r / \Delta^{a b}$ & شن (درصد) \\
\hline$V / \Lambda \pm \circ / \circ q^{a}$ & $V / \Lambda \pm \circ / \circ q^{a}$ & $V / 9 \pm 0 / 09^{a}$ & اسيديته \\
\hline
\end{tabular}

منطقه ميزان آن يكسان بود (جدول ().

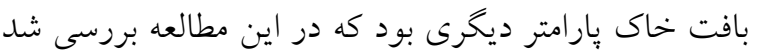

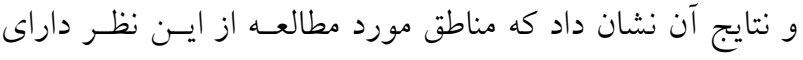

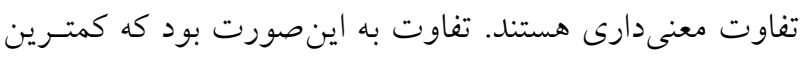
رس در منطقـهـ دور از رودخانـه مشـاهده شــــ و داراى تفــاوت

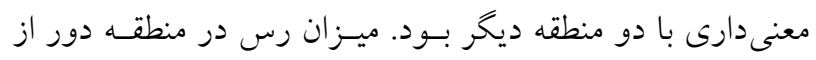

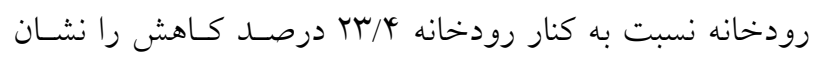

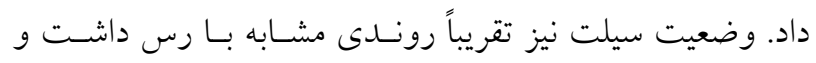

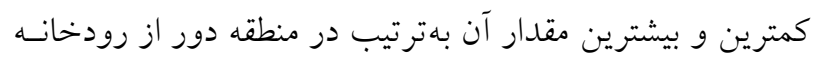

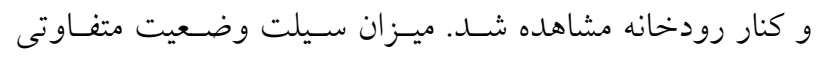

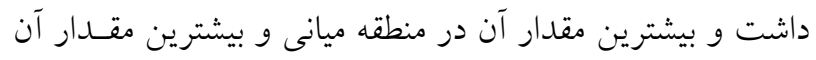

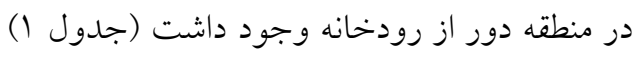

\section{تراكم اسبور و آغشتخى ريشه}

وضعيت تراكم اسيور نشـان داد كـه بيشـترين مقــدار اسـيور در منطقه ميـانى مشـاهده شـــ و داراى اخـتلاف معنسى دارى بـا دو منطقه ديخر بود. در اين مطالعه متوسط تراكم اسيور در ينج گرم منام خاك در منطقه كنار رودخانه، ميانى و دور از رودخانه بهترتيـب

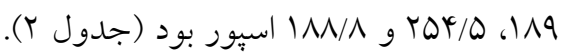

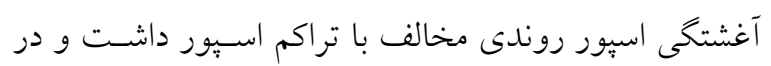

كرد كه برخى از متغيرهاى مورد مطالعه داراى تفاوت معنىدارى

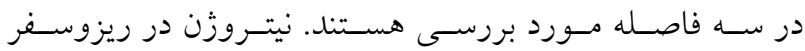
درختجههاى گز در مجاورت رودخانه داراى بيشـترين مقــدار و

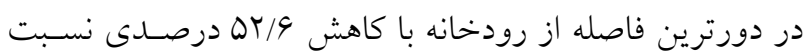
به كنار رودخانه داراى كمترين مقدار بود. به كونهاى كـه تفـاوت معنى دارى در ميزان نيتروزن در منطقه مجاور رودخانه نسبت به به بهائ

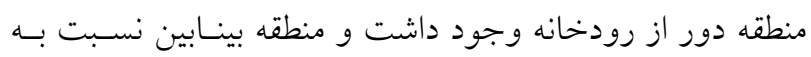
دو منطقه ديخر تفاوت معنىدارى نداشت (جدول (1).

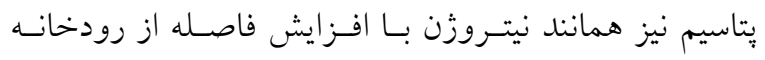

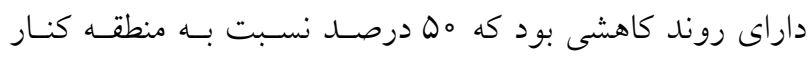
رودخانه كاهش داشت. روند معنى دارى بِّاسيم هماند نيتـروزن داراى تفاوت معنىدار در منطقه مجاور رودخانه و منطقه دور از رودخانه بود. درحالى كه فسـفر هـيج اخستلاف معنسى دارى بـين

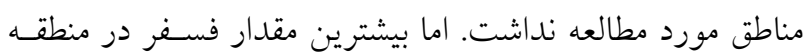
ميانى مشاهده شد و كمترين مقدار آن در منطقه دور از رودخانه

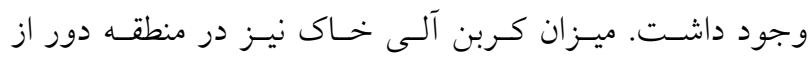

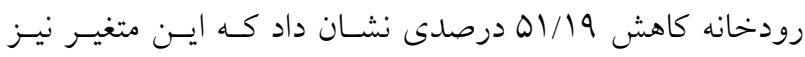
داراى اختلاف معنى دارى در مناطق مورد مطالعه مىباشد. نتسايج

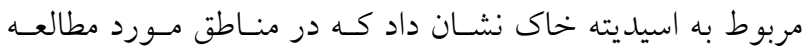

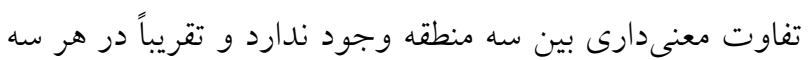


جدول r. تراكم اسبور و آغشتخى اسِور در منطقه مورد مطالعه (ميانخين 土 اشتباه معيار)

\begin{tabular}{|c|c|c|c|}
\hline منطقه دور از رودخانه & منطقه ميانى & منطقه كنار رودخانه & \\
\hline$\Lambda \circ / / V \pm Y / \Delta^{a}$ & $V \Psi / V V \pm Y / q^{b}$ & $\Lambda r / r V \pm 1 / q^{a}$ & آغشتخى ريشه (درصد) \\
\hline $1 \Lambda \Lambda / \Lambda \pm 19 / Y^{b}$ & $r \Delta Y / \Delta \pm 19 / \Delta^{a}$ & $119 / \circ \pm 19 / 9^{b}$ & تراكم اسيور (تعداد در ه كرم خاك) \\
\hline
\end{tabular}

حروف مختلف در يك سطر اختلاف معنىدارى در سطح ه درصد را نشان مىدهند.

\begin{tabular}{|c|c|c|c|c|c|c|c|c|c|c|}
\hline تراكم اسبور & كلنيزاسيون & $\mathrm{pH}$ & شن & سيلت & رس & يتاسيم & فسفر & كربن آلى & نيتروزن & \\
\hline & & & & & & & & & 1 & نيتروزن \\
\hline & & & & & & & & 1 & $\circ / 999^{* *}$ & كربن آلى \\
\hline & & & & & & & 1 & $0 / 4 r q$ & o/4ka & فسفر \\
\hline & & & & & & 1 & ०० YI & - $/ Q Y_{0}{ }^{*}$ & - /DrQ* & يتاسيم \\
\hline & & & & & 1 & - /094* & $\circ / \Upsilon \wedge \circ$ & גוז/ס & Tr/T & رس \\
\hline & & & & 1 & $\circ / V Y V^{* *}$ & $0|94|^{*}$ & . & $0 / \mu 19$ & . MIV & سيلت \\
\hline & & & 1 & $-0 / 991^{* *}$ & $-\circ / \wedge \circ \Delta^{* *}$ & $-0 /\left.9 \Lambda\right|^{* *}$ & $0 / Y 9 V$ & -o/r & - - & شن \\
\hline & & 1 & $.0 \Delta Q$ & $-0 / 041$ & -o/YKY & OMKY & $\circ / 1 \wedge 。$ & $0 / 499$ & $\circ / 4 \circ r$ & $\mathrm{pH}$ \\
\hline & 1 & $-0 / r q \wedge$ & מז/I & $\circ / 1 \circ V$ & $-0 / 041$ & o/DFF* & $-\circ / Y \circ \circ$ & DTH & O/MYG & آغشتخى \\
\hline 1 & $-0 / T \Lambda Y$ & -o/MGY & $-0 / 19 \mu$ & $0 / 1 T^{\prime}$ & $\circ / \wedge \wedge$ & $-0 / 109$ & $\circ / T V V^{c}$ & $-0 / Y 90$ & $-0 / T V Y$ & تراكم \\
\hline
\end{tabular}

يتاسـيم و نيتـروزن وجـود داشـت. همجنـين همبســـى مثبـت معنى دارى بين بتاسيم با رس و سيلت مشاهده شد در حالى كـه يتاسيم داراى همبستخى منفى با ميـزان شـن خـاك بـود. ديخــ

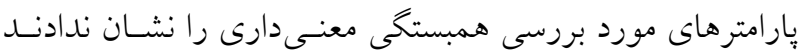

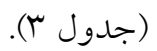

\section{بحث}

قارجهاى ميكوريز اركانيسمهاى مهمى هستند كه نقش مهمى را

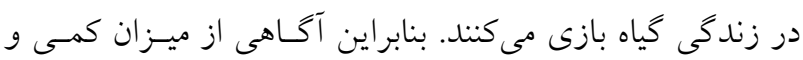

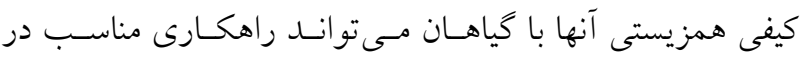
جهت مديريت بهتر جنخـل هـاى مـورد مطالعـه باشـد. در ايسن مطالعه مشخص شد قارجزاى ميكوريز داراى همزيستى بـالايى مئ
منطقه ميانى كمترين ميزان آغشتخى مشاهده شد. بهكونسهاى

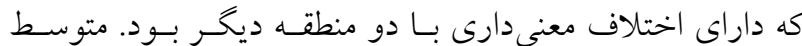
ميزان آغشتخى در منطقه كنار رودخانه، ميانى و دور از رودخانه

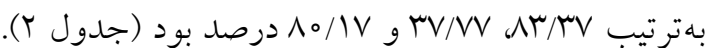
همبستخى بين خصوصيات فيزيكى و شيميايى خاك، تـراكم اسيور و آغشتخى نتايج نشان داد كه بين تراكم اسـيور و ديخــ يارامترهـاى مـورد بررسى هيج گونه همبستكى معنى دارى ديله نشد. درحالى كه بين ميزان آغشتخى ريشه و يتاسيم خاك همبستكى مثبت معنى دارى در سطح ينج درصد مشاهده شد (جدول r). در اين مطالعه همبستخى معنى دارى بـين كـربن الى خـاك، 


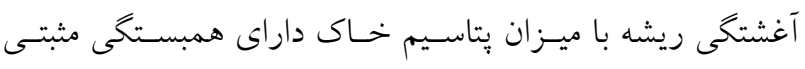

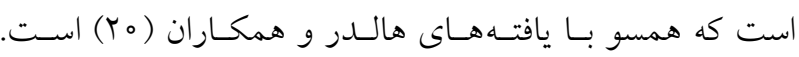

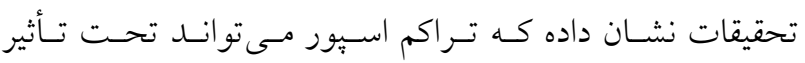

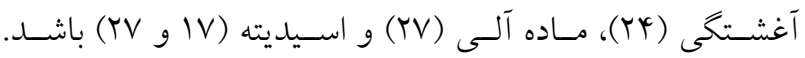

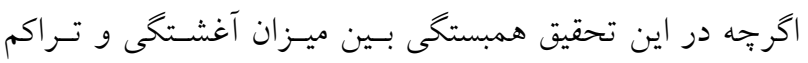

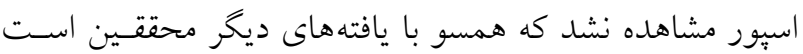

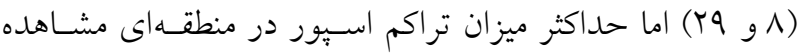

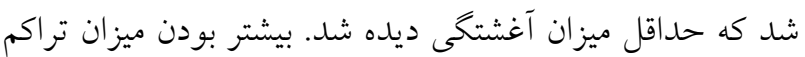

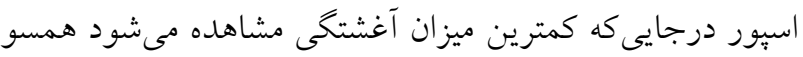

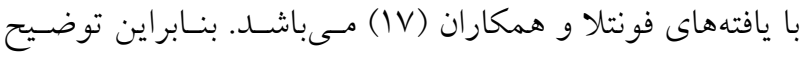

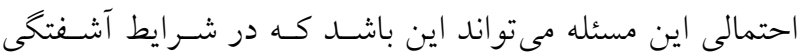

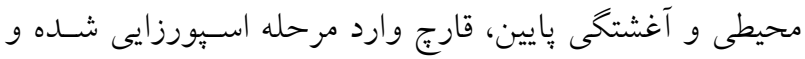
انرزى خود را بر توليد اسبور بيشتر بممنظور اطمينان از بقا خـود در آينده كذاشته است. از ميان خصوصيات فيزيكى و شيميايى خاك مـورد مطالعهـ

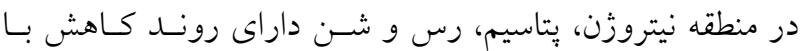
افزايش فاصله از رودخانه بودند. بنسابراين دورى و نزديكسى بـهـ

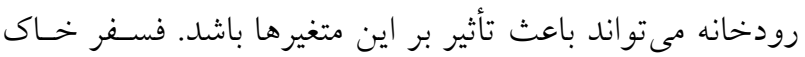

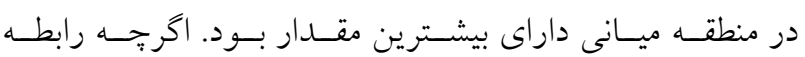
معنى دارى بين ميزان فسفر خاى و آغشتكى در اين مطالعه ديده

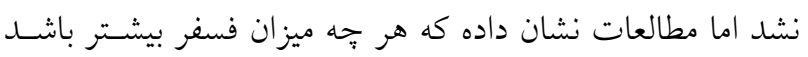

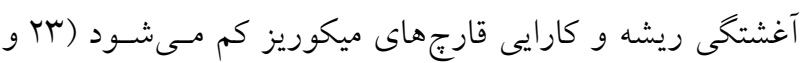

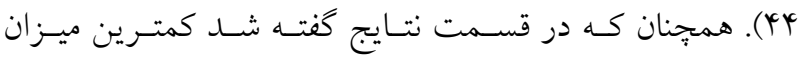

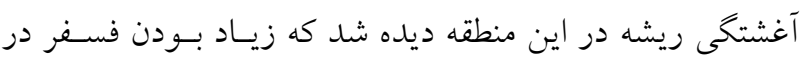
اين منطقه مىتواند باعث كاهش آغشتخى ريشه در ايــن منطقـه

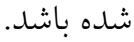

بـا كـز (T. arceuthoides) هسـتند كـه ايـن نتيجـهـ بــرخلاف

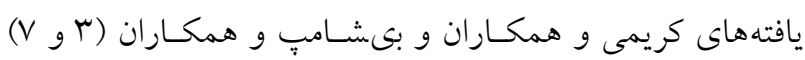

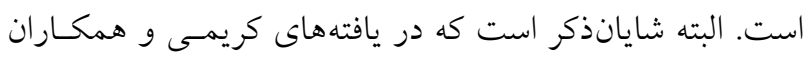

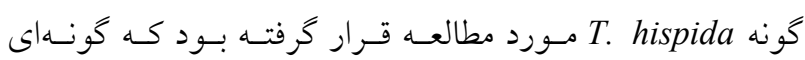
متفاوت نسبت به اين تحقيق بود. جر اكسه ايـن محققسين عنسوان

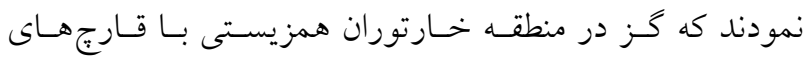
ميكوريز اربوسكولار ندارد. البته شايان ذكر است كه در مطالعـه

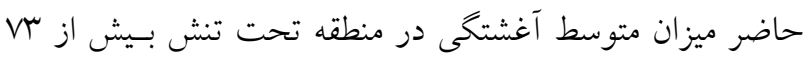

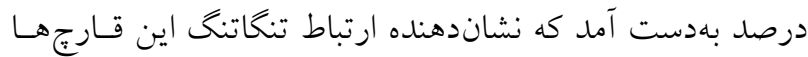

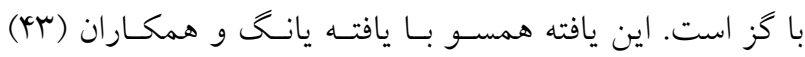

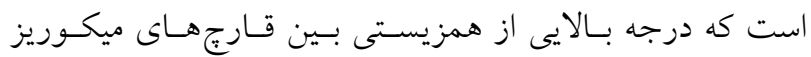
اربوسكولار را با گز گزارش دادند.

در اين مطالعه مشخص شد كه دورى و نزديكى به رودخانه

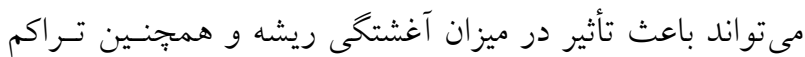
اسيور در خاك شود. به كونهاى كه كمترين ميزان آغشتخى ريشه

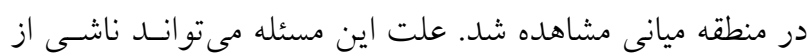
وجود معدن شن و ماسه و درنتيجه آن رفت و آمد ماشسينهـا و

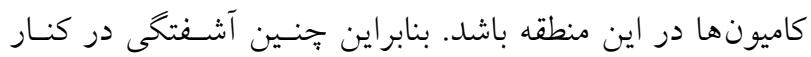
وجود كذر كاههاى روستايى و رفت و آمــ ناشسى از روستاييان

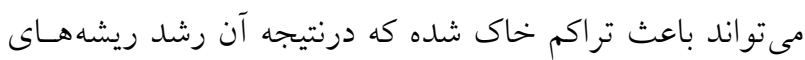

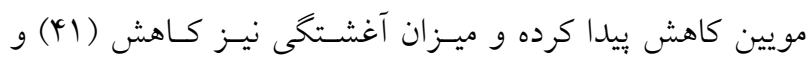

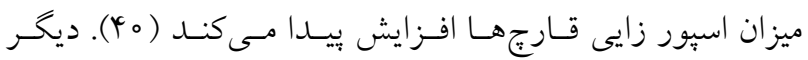

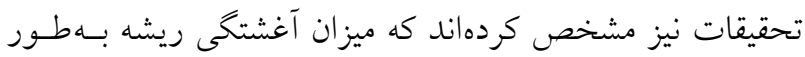

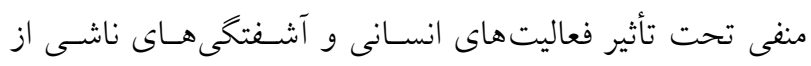

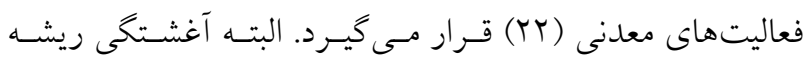

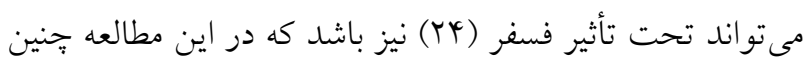

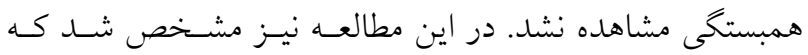

\section{منابع مورد استفاده}

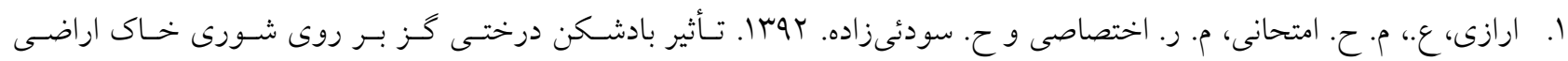

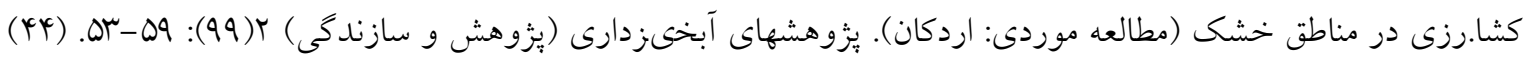

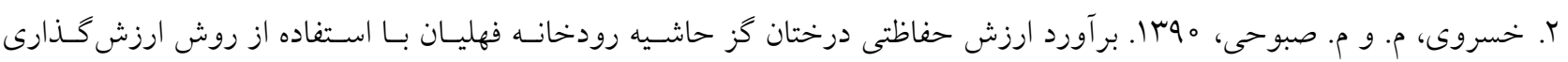




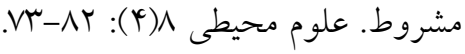

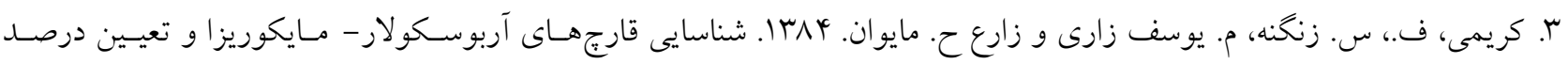

$$
\begin{aligned}
& \text { همزيستى در ذخيرهكاه بيوسفر خارتوران. علوم محيطى ه ا: M-M }
\end{aligned}
$$

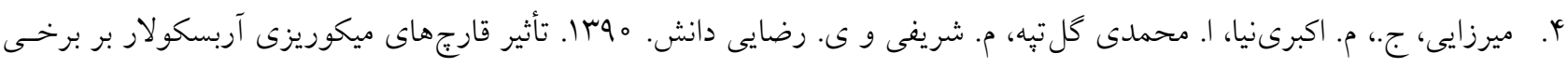

$$
\begin{aligned}
& \text { ويز كىهاى مرفولوزيك و فيزيولوزيك نهالهاى خنجوى (Pistacia khinjuk) تحت تنش خشكى. فصلنامه تحقيقـات جنخـل و } \\
& \text { صنوبر ايران r(Y) }
\end{aligned}
$$

5. Augé, R. M. 2001. Water relations, drought and vesicular-arbuscular mycorrhizal symbiosis. Mycorrhiza. 11: 3-42.

6. Bago, B., P. E. Pfeffer and Y. Shachar-Hill. 2000. Carbon metabolism and transport in arbuscular mycorrhizas. New Phytol. 124: 949-958.

7. Beauchamp, V. B., J. C. Stromberg and J. C. Stutz. 2005. Interactions between Tamarix ramosissima (saltcedar), Populus fremontii (cottonwood), and mycorrhizal fungi: Effects on seedling growth and plant species coexistence. Plant Soil 275: 221-231.

8. Becerra, A. G., M. Cabello, M. R. Zak and N. Bartoloni. 2009. Arbuscular mycorrhizae of dominant plant species in Yungas forests, Argentina. Mycologia. 101(5): 612-621.

9. Biermann, B. and R. G. Linderman. 1981. Quantifying vesicular-arbuscular mycorrhizae: poposed method towards standardization. New Phytol. 87: 63-67.

10. Bremner, J. M. and C. S. Mulvaney. 1982. Nitrogen total. PP: 595-624. In: Miller RH, Kieney DR (Ed.), Method of soil analysis- part 2: chemical and microbiological methods, 2nd edn. Agronomy series No. 9. American Society for Agronomy and Soil Sciences, Madison.

11. Burton, M. L., L. J. Samuelson and S. Pan. 2005. Riparian woody plant diversity and forest structure along an urban-rural gradient. Urban. Ecosyst. 8: 93-106.

12. Carrenho, R., S. F. B. Trufem, V. L. R. Bononi and E. S. Silva. 2007. The effect of different soil properties on arbuscular mycorrhizal colonization of peanuts, sorghum and maize. Acta. Bot. Brasilica 21(3): 723-730.

13.Ellis, L. M. 2001. Short term responses of woody plants to fire in a Rio Grande riparian forest, central New Mexico, U.S.A. Biol. Conserv. 97: 159-170.

14.Eskelinen, A., S. Stark and M Mannisto. 2009. Links between plant community composition, soil organic matter quality and microbial communities in contrasting tundra habitats. Oecologia 161: 113-123. 39

15.Evelin, H., B. Giri and R. Kapoor. 2012. Contribution of Glomus intraradices inoculation to nutrient acquisition and mitigation of ionic imbalance in NaCl-stressed Trigonella foenum-graecum. Mycorrhiza 22: 203-217.

16. Fontenla, S., R. Godoy, P. Rosso and M. Havrylenko. 1998. Root associations in Austrocedrus forests and seasonal dynamics of arbuscular mycorrhizas. Mycorrhiza 8: 29-33.

17.Gai, J. P. and R. J. Liu. 2003. Effects of soil factors on arbuscular mycorrhizae (AM) fungi around roots of wild plants. Chin. J. Appl. Ecol. 14: 470-472.

18. Gerdemann, J. W. and T. H. Nicloson. 1963. Spores of mycorrhizal Endogone species extracted from soil by wet sieving and decanting. Tran. Brit. Mycol. Soc. 46: 235-238.

19. Greenwald, D. N. and L. B. Brubaker. 2001. A 5000-year record of disturbance and vegetation change in riparian forests of the Queets River, Washington, U.S.A. Can. J. Forest. Res. 31: 1375-1385.

20.Halder, M., S. Akhter, A. S. Mohammad Mahmud, F. Islam, R. Mullick, J. Chandra Joardar, Md. S. Amin, R. Karim, H. Talukder and Md. S. Rahman. 2015. Prevalence of Arbuscular Mycorrhiza Fungi (AMF) colonization in medicinal plant root and response of prevalence with some selected medicinal plants rhizosphere soil properties in BCSIR forest, Chittagong, Bangladesh. J. Pure. Appl. Microbiol. 9(1): 131-140.

21.Hunt, P. G., T. A. Matheny and K. S. Ro. 2007. Nitrous oxide accumulation in soils from riparian buffers of a coastal plain watershed-carbon/ nitrogen ratio control. J. Environ. Qual. 36: 1368-1376.

22.Jasper, D. A., L. K. Abbott and A. D. Robson. 1991. The effect of soil disturbance on vesicular-arbuscular mycorrhizal fungi in soils from different vegetation types. New Phytol. 118: 471-476.

23. Karanika, E. D., O. K. Voulgari, A. P. Mamolos, D. A. Alifragis, D. S. Veresoglou. 2008. Arbuscular mycorrhizal fungi in northern Greece and influence of soil resources on their. Pedobiologia 51: 409-418.

24. Khakpour, O. and J. Khara. 2012. Spore density and root colonization by arbuscular mycorrhizal fungi in some species in the northwest of Iran. Int. Res. J. Appl. Bas. Sci. 3(5): 977-982.

25. Koucher, S. D. and R. Hariss. 2007. Riparian Vegetation, Forest Stewardship Series 10, Davis, CA, University of California Agriculture and Natural Resources. U. C. Agric. Nat. Res. 8240: 1-7.

26. MacGregor-Fors, I., R. Ortega-Álvarez, A. Barrera-Guzmán, L. Sevillano and E. del-Val. 2013. Tamarisk? Avian 
responses to the invasion of saltcedars (Tamarix ramosissima) in Sonora, Mexico. Rev. Mex. Biodivers 84: 12841291.

27. Mathur, N., J. Singh, S. Bohra and A. Vyas. 2007. Arbuscular mycorrhizal statues of Medicinal Halophytes in Saline Areas of Indian Thar Desert. Int. J. Soil. Sci. 2(2): 119-127.

28. Mitsch, W. J. and J. G. Gosselink. 1993. Wetlands. Van Nostrand Reinhold, New York.

29. Moradi, M., A. Shirvany, M. Matinizadeh, V. Etemad, H. R. Naji, H. Abdul-Hamid and S. Sayah. 2014. Arbuscular mycorrhizal fungal symbiosis with Sorbus torminalis does not vary with soil nutrients and enzyme activities across different sites. iForest, 8: 308-313.

30. Olsen, S. R., C. V. Cole, F. S. Watanabe and L. A. Dean. 1954. Estimation of available phosphorus in soils by extraction with sodium bicarbonate. USDA Circular 939: 1-19.

31.Phillips, J. M. and D. S. Hayman. 1970. Improved procedures for clearing and staining parasitic and vesiculararbuscular mycorrhizal fungi for rapid assessment of infection. Tran. Brit. Mycol. Soc. 55: 158-161.

32.Reis, F. S., I. C. F. R. Ferreira and A. Martins. 2012. Effect of the mycorrhizal symbiosis time in the antioxidant activity of fungi and Pinus pinaster roots, stems and leaves. Ind. Crops. Prod. 35: 211-216.

33.Ryan, M. H., D. R. Small and J. E. Ash. 2000. Phosphorus controls the level of colonization by arbuscular mycorrhizal fungi in conventional and biodynamic. Aust. J. Exp. Agric. 40: 663-670.

34.Sjöberg, J. 2005. Arbuscular mycorrhizal fungi-occurrence in Sweden and interaction with a plant pathogenic fungus in barley. Ph.D. Thesis. Swedish Univ Agri Sci, Uppsala.

35. Smith, S. E. and D. J. Read. 2008. Mycorrhizal Symbiosis. Academic Press Inc., London, UK.

36. Soman, S., S. Beyeler, S. E. Kraft, D. Thomas and D. Winstanley. 2007. Ecosystem services from riparian area: a brief summary of the literature. $11 \mathrm{p}$.

37. Thomson, B. D., A. D. Robson and L. K. Abbott. 1986. Effects of phosphorus on the formation of mycorrhizas by Gigaspora calospora and Glomus fasciculatum in relation to root carbohydrates. New Phytol. 103: 751-765.

38. Tockner, K. and J. A. Stanford. 2002. Riverine flood plains: Present state and future trends. Environ. Conserv. 29(3): 308-330.

39. Walkley A and I. A. Black. 1934. An examination of the Degtjareff method for determining organic carbon in soils: Effect of variations in digestion conditions and of inorganic soil constituents. Soil. Sci. 63: 251-263.

40. Wallace, L. L. 1987. Effects of clipping and soil compaction on growth, morphology and mycorrhizal colonization of Schizachyrium scoparium, a C4 bunchgrass. Oecologia 72: 423-428.

41.Walter, A., H. Spies, S. Terjung, R. Kusters, N. Kirchgessner and U. Schurr. 2002. Spatio-temporal dynamics of expansion growth in roots: automatic quantification of diurnal course and temperature response by digital image sequence processing. J. Exp. Bot. 53: 689-698.

42.Wang, G. M., D. P. Stribley, P. B. Tinker and C. walker. 1993. Effects of $\mathrm{pH}$ on arbuscular mycorrhiza I. Field observations on the long-term liming experiments at Rothamsted and Woburn. New phytol. 124: 465-472.

43. Yang, Y., Y. Chen and W. Li. 2008. Arbuscular mycorrhizal fungi infection in desert riparian forest and its environmental implications: A case study in the lower reach of Tarim River. Prog. Nat. Sci. 18: 983-991.

44. Yoshimura, Y., A. Ido, K. Iwase, T. Matsumoto and M. Yamato. 2013. Communities of Arbuscular Mycorrhizal Fungi in the roots of Pyrus pyrifolia var. culta (Japanese Pear) in orchards with variable amounts of soil-available phosphorus. Microbes. Environ. 28 (1): 105-111.

45. Zhaoyong, H., Z. Liyun, F. Gu, C. Peter, T. Changyan and L. Xiaolin. 2006. Diversity of arbuscular mycorrhizal fungi associated with desert ephemerals growing under and beyond the canopies of Tamarisk shrubs. Chinese Sci. Bulletin 51: 132-139. 


\title{
The Effect of Distance from River on Soil Physiochemical Properties, Root Colonization and Spore density of Arbuscular Mycorrhizal Fungi Associated with Salt Cedar
}

\author{
S. Moradi Behbahani ${ }^{1}$, M. Moradi ${ }^{*}$, R. Basiri ${ }^{1}$ and J. Mirzaei ${ }^{2}$
}

(Received: Nov. 1-2015 ; Accepted: June 6-2016)

DOI: 10.18869 /acadpub.jstnar.20.78.67

\begin{abstract}
Salt cedar is widely spread out in most part of the country but there is lack of information about its symbiosis with arbuscular mycorrhizal fungi. Then, the main objective of this study was to evaluate the symbiosis of AMF with salt cedar and its affectability by distance from river and soil physiochemical properties. For this purpose, riparian Maroon forest width was divided to three locations including riverside area, intermediate area and the area far from river with 200-hundred-meter interval. In each site 10 salt cedars were randomly selected and soil plus hair root samples were gathered from the salt cedar rhizosphere. Our result indicated that root colonization and spore density in the intermediate distance had the lowest and highest values, respectively. These values were significantly different compared to the other two sites. The average root colonization percent in the riverside area, intermediate area and the area far from river sites were $82.37,73.77$ and 80.17 , respectively. While the average spore density in the riverside area, intermediate area and the area far from river were 189, 245.5 and 188.8 in five gram soils, respectively. Root colonization had significant positive correlation with soil potassium while spore density had significant correlation with studied soil physiochemical properties. Also, soil nitrogen, organic carbon, potassium and clay showed 52.6, 51.19, 50 and $23.4 \%$ decreasing trend from the riverside area to the area far from river. Regarding this research results, salt cedar showed high level of symbiosis with arbuscular mycorrhizal fungi but this symbiosis could be affected by distance from river in riparian forest.
\end{abstract}

Keywords: Colonization, Mycorrhizal fungi, Phosphorus, Potassium, Salt cedar, Spore density.

1. Dept. of Forestry, Faculty of Natural Resour., Behbahan Khatam Al-Anbia Univ. of Tech., Behbahan, Iran.

2. Dept. of Forest sci., Faculty of Agric., Ilam Univ., Ilam, Iran.

*: Corresponding Author, Email: moradi4@gmail.com 